\title{
Lusotopie
}

Recherches politiques internationales sur les espaces

issus de l'histoire et de la colonisation portugaises

XVIII(2) | 2019

Judaïsmes dans les lusotopies contemporaines

\section{Judaísmos nas lusotopias contemporâneas}

\section{Marta Francisca Topel e Cyril Isnart}

\section{OpenEdition \\ Journals}

\section{Edição electrónica}

URL: https://journals.openedition.org/lusotopie/4054

ISSN: 1768-3084

Editora

Idemec - UMR 7307

\section{Edição impressa}

Data de publição: 1 dezembro 2019

Paginação: 143-147

ISSN: $1257-0273$

\section{Refêrencia eletrónica}

Marta Francisca Topel e Cyril Isnart, «Judaísmos nas lusotopias contemporâneas», Lusotopie [Online], XVIII(2) | 2019, posto online no dia 02 janeiro 2022, consultado o 04 fevereiro 2022. URL: http:// journals.openedition.org/lusotopie/4054

Este documento foi criado de forma automática no dia 4 fevereiro 2022

Lusotopie 


\title{
Judaísmos nas lusotopias contemporâneas
}

\author{
Marta Francisca Topel e Cyril Isnart
}

1 Si pensarmos o judaísmo como uma religião cada vez mais enraizada em territórios específicos e espalhada pelos vários continentes do mundo (Bordes-Benayoun dir. 2015), observaremos que certas comunidades judaicas, por razões históricas ou políticas, têm um relacionamento particular com as suas origens geográficas e culturais portuguesas. Nas lusotopias, ou seja, nos espaços conectados com a história de Portugal, as atividades económicas e a expansão colonial proporcionaram oportunidades favoráveis para as comunidades judaicas até o início da repressão liderada pela inquisição católica. Assim surgiram e desenvolveram-se grupos e individualidades cuja dupla pertença à religião judaica e ao contexto português permitiu criar estratégias de acomodação religiosa, social e cultural (Yovel 2009).

2 Apesar de que os pertinazes impedimentos legais e as construções políticas e simbólicas da alteridade dos judeus eram consideradas como um dado natural, foram criados modelos de vida, estilos rituais, redes de comunicação, vias de mobilidade, engajamentos no destino nacional. Porém, os episódios do passado judaico que evidenciam e determinam formas variadas e complementares das identidades judaicas não se limitam aos do final da Idade Média. Desde os chamados "marranos" (Schwarz 1925; Novinsky 1972, 2001) até as experiências as mais contemporâneas (Pignatelli dir. 2017), as mobilidades desenham uma geografia dinânimca das lusotopias judaicas: fuga à inquisição dos séculos XVI até XVIII (Wachtel 2001), migrações proporcionadas pelos regimes liberais no virar do século XX (Medina e Barromi 1987/1988, Franco 2004), deslocamentos para fora da área das perseguições nazistas (Pimentel 2006, Schaefer 2014) com despertar identitário de descendentes de cristãos novos em Portugal (Leite 2017), ou repercussões das recentes leis de nacionalidade espanholas e portuguesas para os descendentes sefarditas.

3 As múltiplas identidades judaicas contemporâneas estão passando por processos de reconfiguração, revitalização e, por que não, de reinvenção. No caso das identidades judaicas em contextos lusófonos, poder-se-ia afirmar que esses processos têm ganhado 
força redobrada na última década devido a diversos fatores, alguns deles intracomunitários e outros externos, isto é, produto de fenômenos desenvolvidos na sociedade maior compreendida, neste caso, como a sociedade global. Esses tipos de trajetórias articulam-se aos referentes territoriais e históricos diversos como o Estado de Israel, a terra bíblica de Israel, o território medieval d'Al-Andaluz, os espaços de refúgio mediterrânicos, europeus, americanos ou asiáticos. Simultaneamente, os processos de transnacionalização, globalização e rediasporização do judaísmo reconfiguraram alguns traços identitários dessas comunidades através da criação de novas fronteiras religiosas intra-grupais e inter-grupais.

o termo sefardita é fundamental para compreender as novas identidades judaicas no(s) mundo(s) lusófono(s), já que uma parte significativa de atores sociais que se afirmam judeus nessas regiões se conectam a uma ascendência sefardita. Contudo, sempre não surge a mesma apelação para definir e nomear tais grupos, como Bnei Anussim, criptojudeus, marranos, que têm as suas próprias histórias e que remetem às varias camadas sociais e interpretações do passado. Às vezes perdida no esquecimento e recuperada num determinado momento da biografia dos atores, às vezes reprimida há séculos pela Inquisição, a origem sefardita pode ser hoje reivindicada como parte indelével da identidade religiosa ou étnico-religiosa de indivíduos que se definem como judeus. Judeus messiânicos, bispos e pastores de igrejas pentecostais e neopentecostais nos quatro cantos do mundo têm se apropriado da parafernália simbólica e ritual típica do judaísmo, mostrando que há um novo fenômeno com muitas e diversas facetas que revela a atualidade do judaísmo como matriz para, a partir dele, configurar novas identidades religiosas e étnico-religiosas.

5 O presente número da Lusotopie tem como objetivo dar conta de alguns fenômenos particulares nesse emaranhado de grupos que se identificam como judeus de origem sefardita, mais precisamente, de origem portuguesa. $O$ intuito é trazemos para o debate acadêmico olhares díspares sobre realidades históricas e geográficas específicas que representam interesses diversos e refletem horizontes acadêmicos e nacionais singulares. Assim, temos priorizado a experiência direta dos pesquisadores com seu objeto de estudo, escolha que nos parece de importância fundamental para melhor compreender um fenômeno sobre o qual na última década têm se debatido e discutido muito, organizado eventos e publicado um grande acúmulo de trabalhos, mas que, em grande medida, ainda resvala no amadorismo e na apologética de representantes de diversas comunidades que encontraram no judaísmo o cerne de sua identidade. Instâncias que legitimam e deslegitimam o pertencimento ao judaísmo têm se multiplicado, criando novas problemáticas não só de políticas identitárias, mas, também, epistemológicas. Nesse sentido, na última década, principalmente no Brasil, pareceria que a velha pergunta "quem é judeu?", para a qual ao longo dos séculos existiu uma única resposta, deu origem a embates entre diferentes grupos com suas respetivas instâncias legitimadoras e suas respetivas respostas. E se bem que no Brasil esses fenômenos tenham no Brasil um lugar destacado, pela variedades de formas em que se apresenta e pela sua importância demográfica, vemos-los em outras regiões, a exemplo de países da América Latina, da África, da Europa e do Oriente Médio, entre eles, Israel. Para dar luz à diversidade dos destinos contemporâneos do judaísmo, este número da revista Lusotopie propõe a adoção do plural: "judaísmos" e "lusotopias". 0 plural permite questionar e evidenciar as características, os lineamentos, e os ressurgimentos da identificação de grupos ou indivíduos com a sua "origem" portuguesa distante ou imaginada, incorporada ou instrumental, que ativam as 
memórias coletivas (principalmente no que diz respeito às múltiplas Terras Mães), os quadros legais, as estruturas políticas e as regras de convivência religiosa dos contextos em que os mesmos atuam.

6 Como antropólogos, compartilharmos a compreensão de que aprofundar-se nessas novas identidades constitui um desafio que os colaboradores deste número da Lusotopie aceitaram com agrado e com seriedade. Assim, o artigo "A descoberta dos Marranos de Portugal ... no Brasil", de autoria de José Alberto Rodrigues da Silva Tavim, faz um pormenorizado racconto da descoberta dos marranos na historiografia brasileira. Além do mais, o autor nos mostra como esse trabalho acadêmico e jornalístico teve no seu bojo o entendimento de que os marranos e o marranismo, necessariamente, fazem parte da cultura e da identidade brasileiras. O papel de historiadores locais e estrangeiros na descoberta da importância dos cristãos novos na configuração identitária do país é analisada em detalhe, trazendo ao leitor um panorama abrangente do fenômeno em questão.

7 Ainda no Brasil, mas a partir de uma abordagem antropológica, Manoela Carpenedo traz ricos dados etnográficos sobre uma comunidade evangélica judaizante do sul do país. Em "Vivendo a nossa ascendência marrana. Ritual e identidades judaicas entre os evangélicos JuDAIzantes no Brasil", o leitor se depara com uma realidade extremamente complexa, na qual uma congregação cristã evangélica está passando por um processo de incorporação do judaísmo ortodoxo, com sua diversidade de rituais e símbolos. Paralelamente, como nos mostra a autora, seus interlocutores reivindicam raízes marranas, o que desemboca na criação de uma identidade judaica que é, ao mesmo tempo, étnica e religiosa.

8 No seu instigante artigo "Virtually Sephardic? The Marketing and Reception of the New Iberian Laws of Nationality in Israel", Silvina Schammah Gesser, através da análise de documentos e de entrevistas em profundidade, tenta explicar as recentes leis de nacionalidade espanhola e portuguesa que beneficiam indivíduos capazes de demonstrar que são descendentes de judeus sefarditas. Segundo Schammah Gesser, a atribuição de nacionalidade portuguesa e espanhola aos judeus sefarditas, que em princípio poderia ser vista como um ato de reparação simbólica pela expulsão e Inquisição sofridas pelos seus ancestrais, constitui um fenômeno muito mais complexo e levanta questões sobre linguagem, identidade e memória coletiva, sobre exílio e migração, sobre empreendedorismo e mobilidade social e, por último, mas não menos importante, sobre diplomacia e Realpolitik.

9 Finalmente, Romain Simenel e Émilie Stoll descrevem algumas dinâmicas identitárias particulares que demonstram as modalidades de integração, mobilidade e enraizamento de descendentes de Judeus no Brasil e no Marrocos contemporâneos. Cruzando as análises de genealogias de duas famílias da Amazônia e do centro do Marrocos com os seus percursos sociais e revindicações territoriais atuais, os autores apontam os usos das narrativas da origem judaica dos antepassados nas estratégias de preservação das afiliações locais nos ambientes de vida dos protagonistas. Mas uma vez, as trajetórias migratórias judaicas destacam-se com um espaço-tempo de primeira importância para se perceber como indivíduos e grupos instituem e defendem as suas respetivas posições e procedem para criar e conservar uma ligação com território no qual atuam.

10 Os artigos deste número da Lusotopie são um modo de inserir a revista num debate atual, sugerindo, por sua vez, que Sefarad é muito mais do que um termo geográfico 
que, em hebraico, significa Espanha e, por extensão, península ibérica. Sefarad é expressão pletórica em sentidos e em vigor conceitual que os contextos sociais, culturais, religiosos, intelectuais ou históricos ajudam a pensar e inserir nas suas complexidades. Assim, Sefarad ecoa, na atualidade, os diversos modos de construir comunidades judaicas enraizadas nos espaços de vida, mas chama também aos lugares de origem e de desejo, com o duplo horizonte da península ibérica e de Israel. Nalgumas partes do mundo e nalguns grupos judeus ou descendentes de judeus, confundem-se, portanto, os territórios, reais ou imaginários, e os destinos, individuais e coletivos.

\section{BIBLIOGRAFIA}

Bordes-Benayoun, C. dir. 2015, Socio-anthropologie des judaïsmes, Paris, Honoré Champion.

Franco, M. 2004, "Diversão balcânica: os israelitas portugueses de Salónica", Análise social, XXXIX (170): 119-147.

Lehmann, D. 2014, Messianic Jews and 'JUDAIZING' Christians - notes from BrAZIL and Israel. http:// www.davidlehmann.org/adlehmann/2014/01/22/271/.

Leite, N. 2017, Unorthodox Kin. Portuguese Marranos and the Global Search for Belonging, Berkeley, University of California Press.

Medina, J. e Barromi, J. 1987/1988, “O projecto de colonização judaica em Angola”, Clio, 6: 79-105. Novinsky, A. 1972, Cristãos novos na Bahia. São Paulo: Perspectiva.

Novinsky, A. 2001, “Os cristãos-novos no Brasil colonial: reflexões sobre a questão do marranismo", Tempo, 6-11.

Pignatelli, M. dir. 2017, Judeus e Cristãos Novos no Mundo Lusófono, Lisboa, Colibri.

Pimentel, I. 2006, Judeus em Portugal Durante a II Guerra Mundial, Lisboa, A esfera dos livros.

Schaefer, A. 2014, Portugal e os refugiados judeus provenientes do território alemão, Coimbra, Imprensa da Universidade de Coimbra.

Schwarz, S. 1925, Os Cristãos Novos em Portugal no século XX, Lisboa. Wachtel, N. 2001, La foi du souvenir. Labyrinthes marranes, Paris, Seuil.

Yovel, Y. 2009, The Other Within: The Marranos: Split Identity and Emerging Modernity, Princeton University Press.

\section{AUTORES}

\section{MARTA FRANCISCA TOPEL}

Professor

Universidade de São Paulo, Brasil

mftopel[at]usp.br 


\section{CYRIL ISNART}

Chargé de recherche

Aix Marseille Univ, CNRS, UMR IDEMEC, Aix-en-Provence, França

isnartc[at]gmail.com 